\title{
Commentary
}

\section{Prophylactic HPV vaccination - current status}

\author{
Kanishka Karunaratne \\ Sri Lanka Journal of Obstetrics and Gynaecology 2010; 32: 25-26
}

Enormous public interest has been generated over the last one year with the licensing of two HPV vaccines in the world designed to prevent human papilloma virus (HPV) and cervical cancer.

Cervical cancer is globalised and the burden of the disease is simply enormous. Every year 500,000 women around the world are diagnosed as new cases while more than half succumb to the disease. Around $80 \%$ of the deaths occur in developing countries. As majority of women are in the late reproductive age group there is serious impact on the medical system and society at large, as well as on the family and individual. Incidence of cervical cancer in Sri Lanka is $9 / 100,000$ population. Most (around 70\%) are diagnosed in advanced stages, due to lack of organized screening programme.

Association of HPV infection and cervical cancer has been proven beyond doubt by molecular studies. There are at least over 100 subtypes specific for human infection out of which HPV 16 and 18 contribute for at least 70 to $80 \%$ of cervical cancers world wide ${ }^{1}$. Transmission of this virus occurs largely during sexual intercourse. Due to its ability of high skin to skin transmission condoms give limited protection. Other factors influencing progress of HPV infection include smoking, long term use of oral contraceptives, high parity, HIV infection and immunosuppression².

The rationale of HPV vaccination is based on the association of HPV infection in cervical carcinogenesis. The prevention of this primary event of acquiring infection will preclude the development of cytological abnormalities which are precancerous. The HPV infection is asymptomatic and does not cause acute damage to the cervix. It is the persistent infection with a large viral load which causes this change. There is a long lag phase of 10 to 15 years before these epithelial abnormalities progress to a cancer.

The concept of preventing a viral infection to prevent a cancer which might otherwise will not occur

\footnotetext{
${ }^{1}$ Consultant Gynaecologist, National Cancer Institute, Maharagama, Sri Lanka.

Correspondence: Kanishka Karunaratne

E-mail: kushank@sltnet.lk
}

for 15 years is novel and differs from the usual role of vaccines which is to prevent an infection that causes an acute morbidity. Perhaps the closest model similar to the HPV vaccine is Hepatitis B where it reduces the incidence of hepatocellular cancer by preventing the acquisition of the virus. Low level of hepatocellular cancer now being seen in far East is due to mass scale vaccination programmes.

In many developed countries secondary prevention is well established by cervical screening programmes. It is being estimated to prevent $80 \%$ of all causes of cervical cancer ${ }^{3}$. Success of these programmes are due to its high population coverage and rigorous quality assurance ${ }^{4}$. However, the strategy of primary prevention would reduce the cost and morbidity associated with the management of abnormal cytology.

Proof of principle trials have shown the vaccines are well tolerated and highly immunogenic, generating antibody response at least 100 fold higher than those observed in natural infections ${ }^{5}$. It has also been shown that the vaccines are more than $90 \%$ effective at preventing type 16/18 associated cervical intraepithelial neoplasia $(\mathrm{CIN})^{6}$.

The principle of prophylactic vaccination relies on the generation of neutralizing antibodies against the high risk HPV types. Virus like particles (VLPs) that structurally mimick the native virions can be produced by incorporating the L protein fraction of the virus. Currently two licensed prophylactic vaccines have been developed and tested in large randomized trials $s^{7,8,9,10}$. One is a quadrivalent vaccine directed against HPV subtypes 16, 18, 6 and 11. This vaccine is designed to prevent both cervical cancer and genital warts. The divalent vaccine acts against subtypes 16 and 18 and designed solely against prevention of cervical cancer.

The quadrivalent vaccine is manufactured in yeast and uses an aluminium adjuvant. Divalent vaccine has incorporated a novel adjuvant ASO4 (monophosphoride lipase A adsorbed on aluminium hydroxide) which is highly immunogenic. Recent studies show that the bivalent vaccine provides a significant cross protection against CIN 2+ associated types 31,33 and 45 . On the other hand the quadrivalent vaccine provides cross protection against CIN 2+ associated types 31 . 
The vaccine is given in 3 doses at 0,1 and 6 months intramuscularly to the deltoid region.

Side effects are minimal with the most common side effect being seen mainly at the injection site. However, the uncommon side effects documented such as gastrointestinal symptoms, pruritus, urticaria, arthralgia, bronchospasms and dizziness differs according to the vaccine types.

The vaccine has to be stored at $2-8^{\circ} \mathrm{C}$. It also can be given simultaneously with other vaccinations. The vaccine has been licensed in many countries including Sri Lanka. In Europe and North America it has been incorporated in to school vaccination programmes. The optimal age of vaccination is preadolescent age. Hence it is recommended to females aged 9-16 years before sexual debut. Catch up vaccination also has been recommended to females up to 26 years. It is recommended during lactation but should be avoided during pregnancy. Current evidence suggest that immunogenicity following vaccination persist for 10 years and possible need for booster can only be determined by further follow up data.

There are a number of other key issues to be considered in the implementation of vaccination programmes. These include the following:

- The implications of the cervical screening in the presence of vaccination programmes.

- The importance of developing public confidence and getting a sufficient understanding of their purpose.

- The prospects for getting these vaccines into resource-poor countries where the vaccine is least affordable.

The challenges need to be addressed, particularly the need to achieve primary prevention in countries with no means of secondary prevention. If that were to happen HPV vaccination could rank along side contraception as a mean of preventing suffering and death in women world wide.

\section{References}

1. Smith JS, Lindsay L, Hoots B, et al. Human papilloma virus type distribution in invasive cervical cancer and high-grade cervical lesions: A meta-analysis update. International Journal of Cancer 2007; 121: 621-32.

2. Castellsague' X, Diaz M, De Sanjose S, et al. Worldwide human papilloma virus etiology of cervical adenocarcinoma and its cofactors: Implication for screening and prevention. Journal of National Cancer Institute 2006; 98: 303-15.

3. NHS CSP publications, Cervical screening reviews 2005 and 2006, 1-29.

www.cancerscreening.nhs.uk

4. Peto J, Gilham C, Fletcher O, Mathews FE. The cervical screening epidemic that screening has prevented in the UK. Lancet 2004; 364: 249-56.

5. Kimbauer R, Booy F, Cheng N, et al. Papilloma virus L1 major capsid protein self-assembles into virus like particles that re highly immunogenoic. Proceedings of the National Academy of Science, USA, 1992; 89: 12180-4.

6. Harro CD, Pang YY, Roden RB, et al. Safety and immunogenicity trial I adult volunteers of a human papilloma virus 16 L1 virus-like particle vaccine. Journal of National Cancer Institute 2001; 93: 284-92.

7. Villa LL, Costa RL, Petta CA, et al. Prophylactic quadrivalent human papilloma virus (types 6, 11, 16 and 18) L1 virus-like particle vaccine in young women: A randomized double-blind placebo-controlled multicentre phase II efficacy trial. Lancet Oncology 2005; 6: 271-8.

8. Harper DM, Franco EL, Wheeler C, et al. Glaxosmithkline HPV Vaccine Study Group. Efficacy of a bivalent L1 viruslike particle vaccine in prevention on infection with human papilloma virus types 16 and 18 in young women: A randomized control trial. Lancet 2004; 364: 1757-65.

9. FUTURE II Study Group. Quadrivalent vaccine against human papilloma virus to prevent high-grade cervical lesions. New England Journal of Medicine 2007; 356(19): 1915-27.

10. Paavonen J, Naud P, Salmeron J, Wheeler CM, Chow $\mathrm{SN}$, et al. Efficacy of human papilloma virus (HPV) 16/18 ASO4-adjuvanated vaccine against cervical infection and precancer caused by oncogenic HPV types (PATRICIA): final analysis of a double-blind, randomized study in young women. Lancet 2009; 374: 268-70. 